\title{
THE EFFECT OF FOOD CONSUMPTION ON THE TOXICOKINETICS OF BENZO(A)PYRENE
} AND 2,2',4,4',5,5'- HEXACHLOROBIPHENYL IN MYSIS RELICTA

Peter F. Landrum1, William A. Frez ${ }^{2}$, and Milagros S. Simmons ${ }^{3}$

1. Great Lakes Environmental Research Laboratory, 2205 Commonwealth Blvd., Ann Arbor, MI 48105

2. Environmental Control Technology Corp., 3985 Research Park Dr., Ann Arbor, Ml 48108

3. Department of Environmental and Industrial Health, The University of Michigan, Ann Arbor, MI 48109

(Received in USA 10 June 1992; accepted 11 June 1992)

The relative importance of water and ingested food as possible avenues of contaminant accumulation was examined. Mysis relicta was exposed to two representative non-polar contaminants: benzo(a)pyrene (BaP) and $2,2^{\prime}, 4,4^{\prime}, 5,5^{\prime}$-hexachlorobiphenyl (HCB). The accumulation was examined kinetically in the presence and absence of two food types, Daphnia pulex (water flea) and Tabellaria flocculosa (a diatom). The availability of either food enhanced HCB accumulation and reduced BaP accumulation. Feeding did not affect HCB elimination but enhanced BaP elimination. The BaP was eliminated primarily as metabolites. Essentially all of the elimination occurred via the fecal route for both compounds. The fraction of the accumulation via ingestion of contaminated food was greater when mysids fed on Daphnia than Tabellaria and was greater for HCB than BaP.

\section{Introduction}

The role of ingested contaminant in bioaccumulation is important to fully understand contaminant transport in aquatic ecosystems and, specifically, the importance of biomagnification. If significant biomagnification occurs, energy transfer to upper trophic levels with the concomitant flow of contaminant influences contaminant fate. Such trophic transfer may augment the potential deleterious health effects on higher trophic levels by increasing the contaminant exposure.

Until recently, evidence for the popular conception of food chain transfer and the importance of biomagnification was the subject of much debate (Biddinger and Gloss 1984). Laboratory data indicated that the extent of xenobiotic accumulation from food is quite variable and may depend on (1) the extent to which contaminants are metabolized and subsequently eliminated (Neff 1979) and (2) the differences between the concentrations in the water and food sources (Opperhuizen 1991). Accumulation of p, $p^{\prime}$-DDT from food ranged between $30 \%$ and $100 \%$ of the p,p'-DDT body burden for fish (Macek and Korn 1970, Macek et al. 1970, Rhead and Perkins 1984) and the extent of kepone accumulation from a dietary source for shrimp was additive to the water source (Fisher and Clark 1990). Further, both feeding rate and food concentration affected the efficiency of accumulation for compounds accumulated from food (Opperhuizen and Schrap 1988, Weston 1990). Thus, food chain transfer is expected to produce concentrations above those that can be achieved through water-borne accumulation alone (Gobas et al. 1988).

Modeling efforts to describe the extent of hydrophobic contaminant accumulation have incorporated food 
chain transfer to bring the models in line with the field data (Thomann and Connolly 1984, Weininger 1978, Connolly and Tonelli 1985, Connolly and Pedersen 1988, Gobas et al. 1988, Connolly 1991). These models have had to assume factors such as contaminant assimilation efficiency and metabolizing capability of the animal. Recent field work has demonstrated that trophic structure, specifically the number of links in the food chain, is important for determining the final contaminant concentrations in the upper trophic levels for polychlorinated biphenyls (PCB) (Rasmussen et al. 1990). This field effort identifies biomagnification and food chain transport as important processes in contaminant accumulation.

in the above models, accumulation by the invertebrates is important for correctly predicting the transfer further up the food chain. However, mathematical models have not been developed to predict the contaminant body burden for invertebrates as a function of the specific kinetics or feeding. Conceptually, the role of feeding on contaminant accumulation by aquatic animals may (1) be additive, (2) negligible or (3) reduce the contaminant body burdens (Biddinger and Gloss 1984). While some experimental work has been performed with warm water species (Biddinger and Gloss 1984, Weston 1990, Fisher and Clark 1990), no research has been conducted to assess the effect of feeding on contaminant accumulation in cold water invertebrates of oligotrophic systems such as those studied by Rasmussen et al. (1990).

Our work examines the effects of food consumption on contaminant accumulation by the invertebrate Mysis relicta, which comprises an integral part of the ecology of the upper Laurentian Great Lakes. M. relicta is a vertically migrating omnivore (Beeton and Bowers 1982), consuming zooplankton (Bowers and Vanderploeg 1982) and algae (Bowers and Grossnickle 1978). Mysids may comprise up to $50 \%$ of the diet of juvenile lake trout (Dryer et al. 1965) and bloater (Wells and Beeton 1963). Because of its role as both predator and prey, M. relicta is a potential food chain vector for contaminants. Our study measured the toxicokinetics, from water and food sources, of the polycyclic aromatic hydrocarbon (PAH), benzo(a)pyrene (BaP) and the polychlorinated biphenyl (PCB) congener, 2,2',4,4',5, '- hexachlorobiphenyl (HCB).

\section{Materials and Methods}

Collection of Mysis rellcta: Mysids were collected at night from Lake Michigan from a station four miles west of Grand Haven, Ml at a maximum depth of $65 \mathrm{~m}$ by obliquely towing a nitex net $(1.0 \mathrm{~m} \times 3.0 \mathrm{~m} ; 565 \mu \mathrm{m}$ mesh, fit with a bayonet-mounted weighted PVC cod-end, $2 \mathrm{~L}$ capacity) near the lake bottom. After collection, the mysids were transferred to aquaria containing approximately $50 \mathrm{~L}$ of hypolimnetic water and kept at approximately $4^{\circ} \mathrm{C}$. The animals were transported to the laboratory within $24 \mathrm{~h}$.

In the laboratory, Mysids were gently transferred to rectangular aquaria containing aerated and charcoalfiltered lakewater at $4^{\circ} \mathrm{C}$. They were held in the dark because of their sensitivity to light (Smith 1970). Water volume changes of approximately $10 \%$ were made weekly to reduce the affects of waste accumulation. The mysids were fed daily rations of fresh trout chow. Approximately every 2 days, unconsumed trout chow was removed to minimize deleterious $B O D$ and $C O D$ effects. Mysids were used for experiments within one month of collection to minimize potential deleterious effects due to containment. 
Daphnia pulex Collection, Growth and Maintenance: Daphnia pulex were frequently collected simultaneously with $M$. relicta. Large, presumably gravid adults were gently seined from the mysid collection and placed in 20 $L$ polyethylene carboys filled with Lake Michigan surface water. The daphnids were then transported to the laboratory and maintained on a light:dark cycle of $12 \mathrm{~h}: 12 \mathrm{~h}$. The daphnids were fed daily with aliquots of (1) unialgal Chlamydomonas oblonga cultures (obtained from H.A. Vanderploeg, Great Lakes Environmental Research Laboratory, NOAA, Ann Arbor, MI.) collected from Lake Huron, (2) a suspension of a water extract of Cerophyll, and (3) water reconstituted yeast cells. Neonates were removed by screening from the initial culture aquaria, using a $400 \mu \mathrm{m}$ mesh nitex net. The neonates were then transferred to fresh filtered lakewater and grown to maturity.

Tabellaria flocculosa Growth and Maintenance: A uni-algal culture of $\underline{T}$. flocculosa collected from Lake Huron was obtained from H.A. Vanderploeg (Great Lakes Environmental Research Laboratory, NOAA, Ann Arbor, MI.). A $100 \mathrm{~mL}$ inoculum was added to sterile WC medium excluding Tris buffer (Stein 1973) and grown to an optically dense, presumably late log phase culture.

Prior to use in feeding studies, the chlorophyll a (chl a) content of culture samples was determined. Aliquots were removed and centrifuged at $1400 \mathrm{~g}$ for $10 \mathrm{~min}$ to concentrate the algal cells. The cells were then added to fresh lakewater to give an approximate concentration of $15 \mathrm{mg}-\mathrm{chl} \underline{\mathrm{a}} \mathrm{m}^{-3}$. In later studies the chl a content was determined along with the mass of $I$. flocculosa, in order to determine the chl a:mass ratio.

Compounds: ${ }^{3} \mathrm{H}$-Benzo(a)pyrene (BaP, specific activity $=23.8 \mathrm{Ci} \mathrm{mMol}^{-1}$ ) was obtained from Amersham while ${ }^{14} \mathrm{C}-2,2$ ', 4,4',5,5'-hexachlorobiphenyl ( $\mathrm{HCB}$, specific activity $\left.=13.1 \mathrm{mCi} \mathrm{mMol}^{-1}\right)$ was obtained from Pathfinder Laboratories (currently Sigma Radiochemicals). The compounds were tested for radiopurity with a combination of thin layer chromatography (TLC) and liquid scintillation spectrometry. The compounds were chromatographed on silica gel plates $(250 \mu \mathrm{m}, \mathrm{E}$ Merck) in hexane:benzene ( $8: 2 \mathrm{~V}: \mathrm{V})$. The silica gel was scraped from the plates at the retention position corresponding to the parent compound and at several other segments, including the origin. Each segment was placed in a separate scintillation vial with $12 \mathrm{~mL}$ scintillation cocktail (3a70B, Research Products International). The radioactivity of the samples was determined on a Packard $460 \mathrm{C}$ scintillation spectrometer. The radiopurity was determined as the percent parent compound activity divided by the total activity for the particular compound under test. All compounds used for study were at least $98 \%$ radiopure. Compounds found to be less than $98 \%$ pure were purified by TLC using the same solvent system as above.

Determination of Xenobiotic Metabolism: During certain experiments, whole mysids, fecal material, and exposure water were analyzed for degradation products. Wet mysids and dried fecal pellets were weighed and extracted in a 1:1 mixture of acetone:ethylacetate (EtOAC) by grinding in a $10 \mathrm{~mm} \times 100 \mathrm{~mm}$ ground glass tissue grinder. The extract slurry was then quantitatively transferred to a conical centrifuge tube, capped with a Teflonlined screw cap, and centrifuged at $1400 \mathrm{~g}$ for $10 \mathrm{~min}$. The supernatant was transferred to a clean centrifuge tube using a Pasteur pipette. The tissue pellet was rinsed and centrifuged three more times, using fresh EtOAc. 
The combined extract was concentrated to $1 \mathrm{~mL}$ or less with a gentle stream of nitrogen. The tissue residue was air dried, placed directly into $12 \mathrm{~mL}$ scintillation cocktail and allowed to soak overnight before being counted.

Aliquots of the concentrated extract were chromatographed on silica gel TLC plates ( $250 \mu \mathrm{m}$ thickness- $E$. Merck). Each TLC plate was developed under a solvent-unsaturated atmosphere using a 4:1 hexane:benzene mixture. The dried plate was cut into 17 one-cm sections that were scraped onto glassine powder paper and placed into vials containing $12 \mathrm{~mL}$ of scintillation cocktail. The radioactivity of each section was determined by liquid scintillation counting.

Water from static uptake studies was pooled and extracted using a liquid-liquid dichloromethane $(D C M) / c y c l o h e x a n e ~ s y s t e m$. The water was extracted three times with a $10 \%$ volume of DCM and three times with a $10 \%$ volume of cyclohexane. The extracts were combined and dried by passing them through granular anhydrous $\mathrm{Na}_{2} \mathrm{SO}_{4}$. The dried extract was then concentrated to approximately $10 \mathrm{~mL}$ using a rotary evaporator, followed by further concentration to $1 \mathrm{~mL}$ using nitrogen. The extracts were analyzed using TLC and scintillation counting, as described earlier.

Toxicokinetic Experiments: Experimentally, a three-compartment model was simulated such that mysids accumulated contaminant from both food and water sources. As references, parallel experiments were conducted to determine the uptake rates from water alone. In the three-compartment experiments, the food sources were pre-equilibrated with a concentration of xenobiotic in water which was the same as that used for the mysid exposure. Methanol was used as a carrier solvent for all experiments, because it has no observable effects on toxicokinetic parameters at concentrations used (approximately $50 \mathrm{mg} \mathrm{L}^{-1}$ )(Landrum, unpublished data).

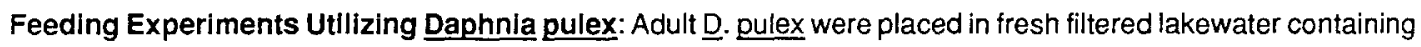
radiolabeled ${ }^{14} \mathrm{C}-\mathrm{HCB}$ ( approximately $200 \mathrm{DPM} \mathrm{mL}{ }^{-1}$ ) and ${ }^{3} \mathrm{H}-\mathrm{BaP}$ (approximately $1000 \mathrm{DPM} \mathrm{mr^{-1 }}$ ). The $\mathrm{D}$. pulex were allowed to accumulate the radiolabeled compound for $48 \mathrm{~h}$ at $4^{\circ} \mathrm{C}$ in the dark. After $24 \mathrm{~h}$ of loading, fresh filtered lakewater was dosed with radiolabeled ${ }^{14} \mathrm{C}-\mathrm{HCB}$ and ${ }^{3} \mathrm{H}-\mathrm{BaP}$ at the same concentrations as above, poured into $700 \mathrm{~mL}$ serum bottles, and capped with Teflon-lined screw caps. At $48 \mathrm{~h}$ after the start of the loading phase, the $\underline{\underline{D}}$. pulex were removed from the loading aquarium and placed in eight, $700 \mathrm{~mL}$ serum bottles. An individual mysid was then placed in each serum bottle. For reference, eight mysids were also placed in bottles containing no $\underline{D}$. pulex for contaminant uptake from water only. The capped bottles were placed on a wheel rotating at approximately 1 revoiution per min (RPM).

At approximately $2,4,12,24$, and $48 \mathrm{~h}$, reference and experimental bottles were removed from the rotating wheel. Two $\mathrm{mL}$ of whole water were sampled and placed in $12 \mathrm{~mL}$ scintillation cocktail for a determination of the total radioactivity present. Mysids and daphnids were recovered by pouring the exposure water through a $400 \mu \mathrm{m}$ screen, rinsing with cold filtered lakewater to remove droplets of radioactive solution, and blotting to dryness. Mysids were weighed wet and placed in $12 \mathrm{~mL}$ scintillation cocktail at least $24 \mathrm{~h}$ prior to counting. Daphnids from each bottle were counted, combined in tared aluminum foil boats, dried at approximately $60^{\circ} \mathrm{C}$ for $48 \mathrm{~h}$, and weighed. The daphnia were also held in $12 \mathrm{~mL}$ scintillation cocktail at least $24 \mathrm{~h}$ prior to counting.

Fecal material was collected from exposure water by applying suction to a $100 \mu \mathrm{L}$ pipette. The fecal material 
was then rinsed and placed in cold filtered lakewater and pipetted into tared aluminum boats. The fecal material was dried at $60^{\circ} \mathrm{C}$ for $48 \mathrm{~h}$ and weighed.

Elimination studies were conducted independently of the uptake studies. Mysids were "loaded" with ${ }^{14} \mathrm{C}-\mathrm{HCB}$ and ${ }^{3} \mathrm{H}-\mathrm{BaP}$ via exposure to contaminated water for $48 \mathrm{~h}$. Fresh adult $\underline{\mathrm{D}}$. pulex were removed from their maintenance aquaria, placed in $700 \mathrm{~mL}$ serum bottles containing filtered lakewater at $4^{\circ} \mathrm{C}$, and kept in the dark. Individual radiolabeled mysids were then transferred to serum bottles containing $\underline{\mathrm{D}}$. pulex and also to reference bottles having no food. The bottles were capped and placed on the rotator wheel at $4^{\circ} \mathrm{C}$ in the dark. Triplicate samples of the reference and the experimental bottles were removed at 2, 4, 8,24, and $48 \mathrm{~h}$ after the start of the elimination phase. Mysids and fecal material were collected and treated as previously discussed. Daphnia were removed using a screen, placed in tared aluminum drying boats, dried at $60^{\circ} \mathrm{C}$ for $48 \mathrm{~h}$, and weighed to estimate the mass of daphnia consumed during the experiment.

Feeding Experiments Utilizing Tabellaria flocculosa: Tabellaria flocculosa cells were harvested by centrifuging aliquots of culture at $1400 \mathrm{~g}$ for $10 \mathrm{~min}$. The cells were resuspended in $50 \mathrm{~mL}$ filtered lakewater dosed with radiolabeled ${ }^{14} \mathrm{C}-\mathrm{HCB}$ (approximately $200 \mathrm{DPM} \mathrm{mL}$ ) and ${ }^{3} \mathrm{H}-\mathrm{BAP}$ (approximately $1000 \mathrm{DPM} \mathrm{mL}{ }^{-1}$ ) at $18^{\circ} \mathrm{C}$ in the dark. At approximately $36 \mathrm{~h}$, fresh filtered lakewater dosed with ${ }^{14} \mathrm{C}-\mathrm{HCB}$ and ${ }^{3} \mathrm{H}-\mathrm{BaP}$ at the above concentrations was poured into $700 \mathrm{~mL}$ serum bottles. Aliquots of the labeled I. flocculosa suspension were pipetted into the serum bottles at concentrations of approximately $15 \mathrm{mg}-\mathrm{chl} \underline{\mathrm{a}} \mathrm{m}^{-3}$. Reference bottles contained radiotracer-dosed water only. Individual mysids were then placed in the serum bottles and the capped bottles were placed on a rotating wheel at $4^{\circ} \mathrm{C}$ in the dark. Mysids were removed at 2, 4, 8, 24, and $48 \mathrm{~h}$ after the start of the uptake phase. The mysids were sampled and prepared as described for the daphnia uptake experiments.

Initially, $\underline{\mathrm{I}}$. flocculosa was quantified on a $\mathrm{mg}-\mathrm{chl}$ a $\mathrm{m}^{\cdot 3}$ basis. However, to adequately determine the mass feeding rate and compare the kinetics with those from the daphnia experiments, the $I$. flocculosa mass was determined in subsequent experiments. Additionally, chl a :mass ratios were determined to convert chl $\underline{a}$ based kinetics data to mass-based kinetics data.

$\mathrm{Chl}$ a was determined on $100 \mathrm{~mL}$ aliquots of filtered (25 mm Gelman AVE glass fiber filters) exposure water. Each filter was then soaked in cold pH-buffered acetone overnight. The absorbance of the extracted chl a was measured on a Turner fluorometer at $520 \mathrm{~nm}$. The chl a concentration was determined by comparison to a standard curve generated by using a spinach chl a (Sigma Inc.) solution in acetone. The radioactivity of the $\mathrm{I}$. flocculosa was determined by filtering $100 \mathrm{~mL}$ of the exposure water through two $25 \mathrm{~mm}$ Gelman AVE glass fiber filters. The cells were then rinsed with approximately $25 \mathrm{~mL}$ of cold filtered lakewater to remove non-absorbed radioactivity.

The radioactivity in the cells was determined by placing the filters in $12 \mathrm{~mL}$ of scintillation cocktail and counting. The second filter was used to estimate the extent of radioactive contaminant sorption on the filters.

In an effort to determine the mass feeding rate of the mysids, the mass of algae associated with each bottle was determined gravimetrically. After sub-samples had been taken for $\mathrm{chl}$ a and radioactivity determinations and fecal pellets had been removed (as described above), the entire volume of water in the bottle was filtered through a rinsed, dried, and tared $25 \mathrm{~mm}$ Gelman AVE glass fiber filter. The filter was removed, placed on a 47 $\mathrm{mm}$ Teflon disc (to prevent adhesion during drying), dried in a desiccator, and weighed. 
The radioactivity of filtered aliquots of water was determined by placing them in $12 \mathrm{~mL}$ of scintillation cocktail and counting them on a Packard 460 Scintillation Counter.

For elimination experiments utilizing $I$. flocculosa, mysids were loaded in the same manner as those utilizing D. pulex. I. flocculosa was concentrated from the culture flasks by centrifugation and resuspension in $700 \mathrm{~mL}$ cold filtered lakewater at a chl a concentration of $15 \mathrm{mg} \mathrm{m}^{-3}$. The mysids were added to the serum bottles that were capped and placed on a rotating wheel ( 1 RPM) at $4^{\circ} \mathrm{C}$ and kept in the dark. The mysids were sampled at $4,8,16,24$, and $48 \mathrm{~h}$. Mysids and fecal pellets were collected, prepared, and analyzed as described earlier.

Kinetic Analyses: The uptake clearance from water was determined for water-only exposures by using a twocompartment mass balance model where the mass of the xenobiotic is conserved (Equation 1).

$$
Q_{a}=\frac{k_{u m} \cdot Q_{t} \cdot\left(1-e^{-\left(k_{u m}+k_{\theta}\right) t}\right)}{\left(k_{u m}+k_{\theta}\right)} \quad \text { Equation (1) }
$$

where,

$Q_{\mathrm{a}}=$ the quantity (ng) of contaminant in the animal,

$t=$ time $(h)$,

$k_{u m}=$ the uptake rate constant from water $\left(h^{-1}\right)$,

$a_{1}=$ the quantity (ng) of contaminant in the system, and

$\mathrm{K}_{\mathrm{a}}=$ the elimination rate constant $\left(\mathrm{h}^{-1}\right)$ of the contaminant from the

animal.

Under mass balance conditions, $Q_{t}=Q_{w}+Q_{a}$ where $Q_{w}$ amount of compound in the water compartment.

Initially, when $Q_{a}$ is very small or if $k_{b}$ is small relative to $k_{u m}$, the uptake clearance can be calculated from a simplification (Equation 2).

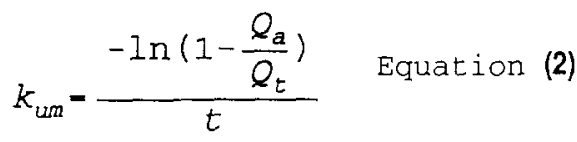

$\mathrm{k}_{u m}$ must then be converted to the system independent uptake clearance $\left(\mathrm{k}_{\mathrm{w}}\right)$ by multiplying by the quantity V/M (Landrum 1983) where,

$V=$ the volume $(\mathrm{mL})$ of the static exposure system, and

$M=$ the mass $(\mathrm{g})$ of animal in the static exposure system.

Conversion to $k_{w}$ is required so that comparisons can be made between experiments.

The elimination rate constants were calculated as the slope of the first order decay model (Equation 3).

$$
\ln C_{a}=\ln C_{a}^{0}-k_{e} \cdot t \quad \text { Equation (3) }
$$

where, $\mathrm{C}_{\mathrm{a}}{ }^{0}=$ the concentration (ng g ${ }^{-1}$ ) of the contaminant in the animal at the start of the elimination phase. Independent elimination rate constants can be added to determine the overall elimination rate constant. 
Consequently, in the presence of feeding, $k_{b}$ is the sum of elimination due to feeding $\left(k_{e 1}\right)$ and elimination due to water exposure $\left(k_{\theta 2}\right)$. The $k_{\theta t}$ was determined independently from water controls while $k_{a 2}$ was determined by difference between $k_{a}$ and $k_{e 1}$.

Uptake from water and food may be expressed mathematically as a three-compartment model (Equation 4).

$$
\frac{d C_{a}}{d t}=k_{w} \bullet C_{w}+k_{f} \bullet C_{f}-k_{e} \bullet C_{a} \quad \text { Equation (4) }
$$

where,

$\mathrm{C}_{\mathrm{a}}=$ the concentration $\left(\mathrm{ng}^{-1}\right)$ of contaminant in the animal,

$\mathrm{t}=$ time (h),

$k_{w}=$ the uptake clearance from water $\left(\mathrm{ml} \mathrm{g}^{-1} \mathrm{~h}^{-1}\right)$,

$\mathrm{C}_{\mathrm{w}}=$ the concentration (ng $\mathrm{mL}^{-1}$ ) of contaminant in water,

$k_{e}=$ the elimination rate constant $\left(h^{-1}\right)$ of the contaminant from the animal,

$k_{1}=$ the uptake clearance $\left(g^{-1} h^{-1}\right)$ from food, and

$\mathrm{C}_{1}=$ the concentration $\left(\mathrm{ng} \mathrm{g}^{-1}\right)$ of contaminant in the food.

Because an exact integral of $\mathrm{dC}_{\mathrm{a}}$ does not exist, Equation 4 must be rearranged to provide a numerical estimate of $k_{1}$ (Equation 5).

$$
k_{f}=\frac{\left[\frac{d C_{a}}{d t}-k_{w} \bullet C_{w}+k_{e} \bullet C_{a}\right]}{C_{f}} \quad \text { Equation (5) }
$$

For this study, $k_{w}$ and $k_{e 1}$ were determined for the water controls while $k_{e 2}$ was determined under feeding conditions. $k_{1}$ was then calculated as described in Equation 5 .

Statistics: Means and slopes were compared using Student's $t$ test and were considered significant if $p<0.05$. Regressions were performed using the linear and nonlinear regression packages in SAS (1985).

\section{Results}

Metabolism of Benzo(a)pyrene: Over the course of a 6 -h exposure at $4^{\circ} \mathrm{C}$ in the dark, approximately $24 \%$ of the radioactivity associated with mysids was found in the form of non-parent material. Of the total non-parent material associated with the animal, $5.7 \%$ was not extractable from the tissue and was, presumably, bound. The calculated metabolic rate for BaP under these conditions is $2.4 \mathrm{pmol} \mathrm{g}^{-1}$ dry weight $\mathrm{h}^{-1}$. Alternatively, $\mathrm{HCB}$ was not metabolized over a $24 \mathrm{~h}$ period under similar conditions.

Because both of the above experiments were conducted as single-labeled experiments, a dual-labeled experiment was conducted to determine if metabolic rates were different. As in the single labeled experiments, 
HCB was not metabolized; BaP was metabolized at a rate of approximately $2.2 \mathrm{pmol}^{-1}$ dry weight $\mathrm{h}^{-1}$.

To crudely assess the mechanism of metabolite elimination, water was extracted from the uptake phase of a kinetics experiment. In the absence of feeding, $86 \pm 2 \%$ of the tritium label was parent BaP and $98 \pm 1 \%$ of the ${ }^{14} \mathrm{C}$ label was parent $\mathrm{HCB}$ from the water extracts. In the mysid, the majority of BaP was parent compound (68 $\pm 7 \%$ ) at the beginning of the experiment; at the end of the experiment, non-parent BaP (70 $\pm 3 \%)$ predominated, suggesting that $\mathrm{BaP}$ metabolites accumulate in the absence of feeding.

$\mathrm{BaP}$ metabolite elimination appears to be influenced by fecal elimination. A TLC analysis of the fecal material indicated that $66 \%$ of the associated radioactivity was non-parent. Unfortunately, the amount of error could not be placed on this estimate because there was not a sufficient mass of fecal material necessary to provide replication.

After a $48 \mathrm{~h}$-exposure to both contaminated water and food, the mysid BaP body burden was $30.3 \pm 6.7 \%$ parent material. However, $77.7 \pm 6.3 \%$ of the $\mathrm{BaP}$ in D. pulex and $94.2 \pm 3.3 \%$ of the BaP in the water was parent material, indicating that chemical changes in the water and/or metabolism by the food source cannot explain the metabolic rate of BaP observed in the mysid. Again, no HCB metabolism or degradation was observed in $\underline{\mathrm{D}}$. pulex or water using these techniques.

Feeding Rates: The feeding rate (FR, grams consumed per gram organism per hour) for mysids exponentially decreased with time for both $\underline{D}$. pulex and $I$. flocculosa (Figure 1). The average number of $\underline{D}$. pulex consumed per hour for three experiments was $0.97 \pm 0.17(n=3)$. The average feeding rates for mysids consuming $\underline{D}$. pulex and I. flocculosa were $0.0008 \pm 0.0003 \mathrm{mg}$ dry wt. $\mathrm{mg}^{-1} \mathrm{~h}^{-1}(\mathrm{n}=8)$ and $0.0019 \pm 0.0006 \mathrm{mg}$ dry wt. $\mathrm{mg}^{-1} \mathrm{~h}^{-1}$ $(n=12)$, respectively. The FR was independent of both the mass of $\underline{D}$. pulex and $I$. flocculosa available. Further, the FR did not depend on the size of the mysids.

A

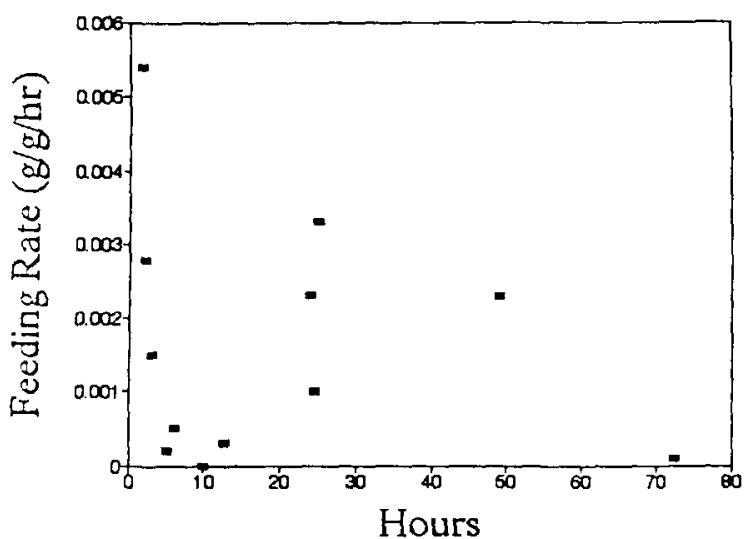

B

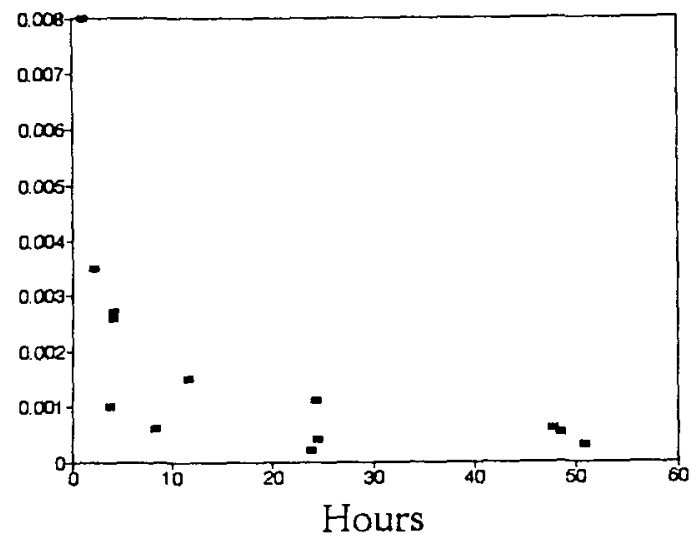

Figure 1. The feeding rate of Mysis relicta consuming Daphnia pulex $(A)$ and Tabellaria flocculosa $(B)$ over time.

D. pulex Feeding Studies: The concentrations of $\mathrm{HCB}$ in the ‥ pulex food source remained relatively constant 
while BaP concentrations appeared to increase (Figure 2).

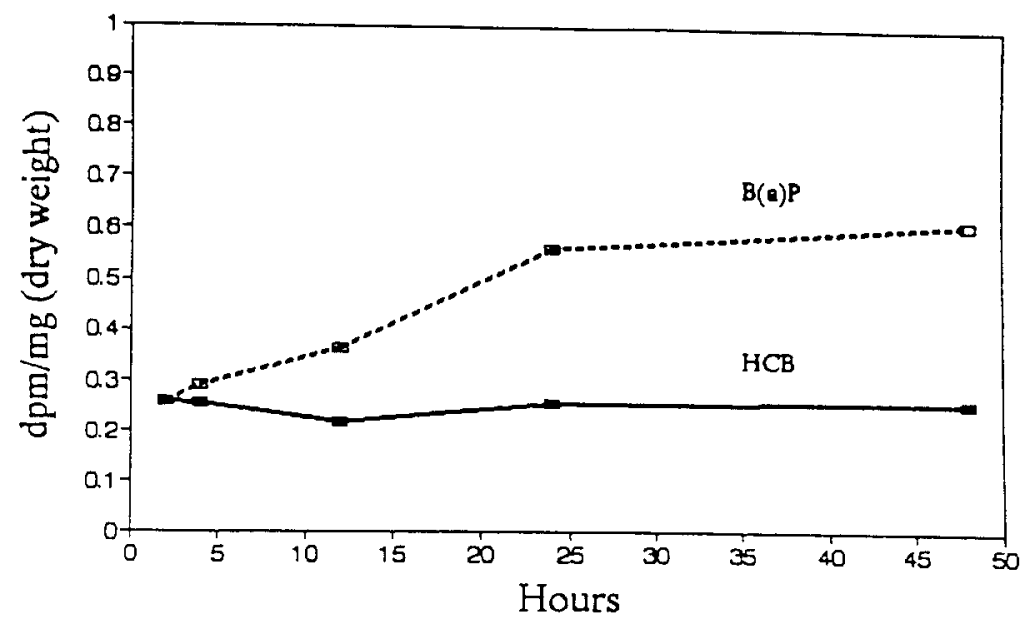

Figure 2. Benzo(a)pyrene and Hexachlorobiphenyl concentrations in Daphnia pulex.

Additionally, the concentrations of $\mathrm{HCB}$ and $\mathrm{BaP}$ in water decreased over time, as expected for a static system. The accumulation of $\mathrm{HCB}$ from a combined food and water source was approximately two times greater than the accumulation from a water source alone; BaP accumulation was approximately 2 times less than from a water source alone (Figure 3 ). $\underline{M}$. relicta that consumed $\underline{D}$. pulex exhibited increased elimination $\left(k_{b}=0.025\right.$ $\left.\pm 0.001 \mathrm{~h}^{-1}\right)$ of BaP compared to unfed mysids $\left(k_{\mathrm{z}}=0.0054 \pm 0.001 \mathrm{~h}^{-1}\right)$.

A

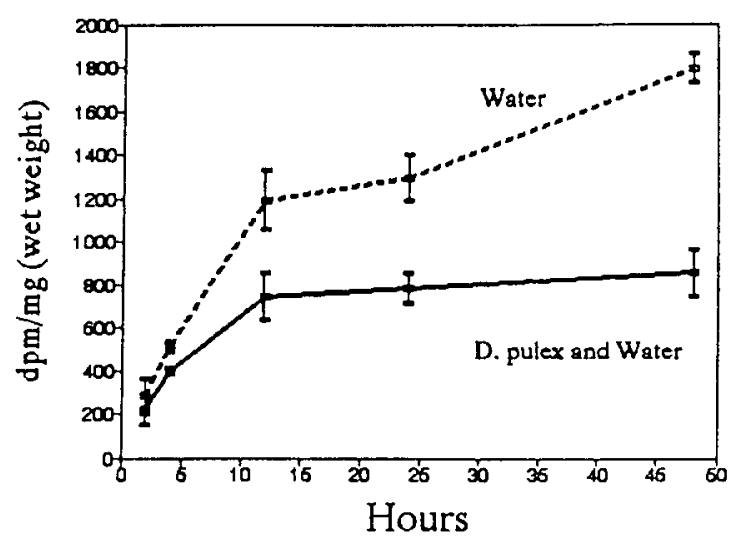

B

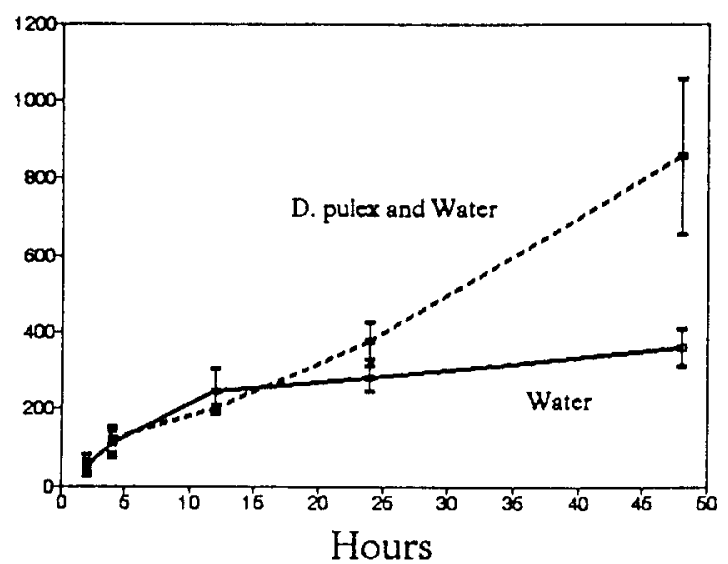

Figure 3. The accumulation of Benzo(a)pyrene (A) and hexachlorobiphenyl $(B)$ in the presence and absence of feeding on $\underline{\text {. pulex. }}$

However, the presence of uncontaminated food did not significantly affect the elimination of HCB by mysids $\left(k_{e}\right.$ 
$=0.0015 \pm 0.0013 \mathrm{~h}^{-1}$, feeding; $k_{8}=0.0067 \pm 0.0047 \mathrm{~h}^{-1}$, non feeding). The amount of $\mathrm{BaP}$ and metabolites associated with fecal material was greater than 2 times that for HCB. Additionally, BaP appeared in the fecal material earlier than HCB (Figure 4).

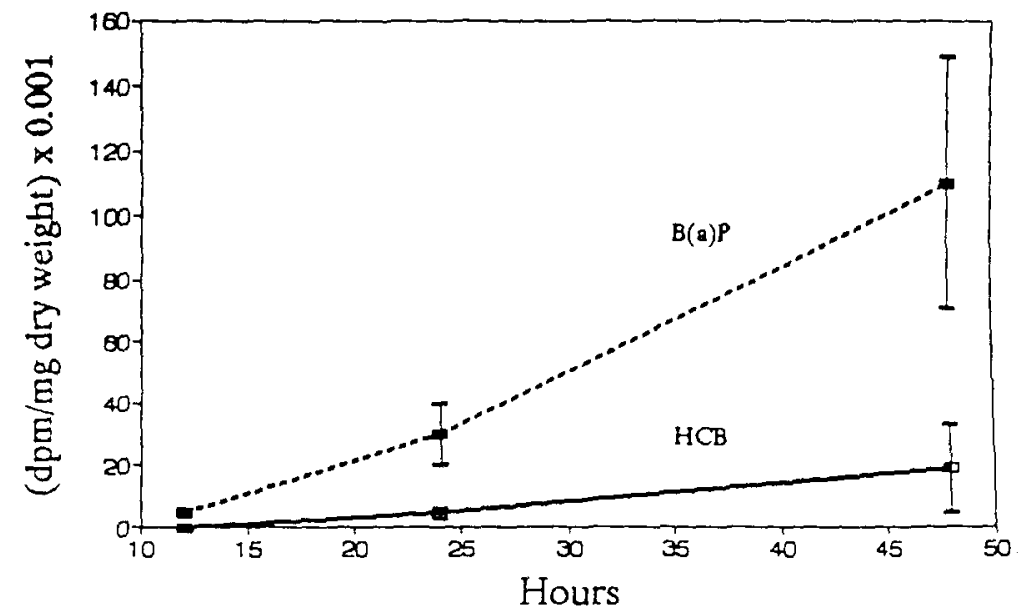

Figure 4. The concentration of benzo(a)pyrene and hexachlorobiphenyl in fecal material eliminated by Mysis relicta while feeding on Daphnia pulex.

Tabellaria flocculosa Feeding Studies: The concentrations of HCB and BaP in I. flocculosa also were relatively constant over the course of the exposure while the concentrations of both decreased in the water. This trend was similar to that observed for the feeding studies with $\underline{D}$. pulex.

HCB concentrations in mysids increased when exposed to $I$. flocculosa and water, relative to animals exposed to water alone (Figure 5). As in the case of the D. pulex experiments, BaP concentrations for mysids exposed to the I. flocculosa and water source were approximately two times less than mysids exposed to water alone (Figure 5).

Mysid elimination of HCB in the presence of $I$. flocculosa and water $\left(k_{\mathrm{e}}=0.0015 \pm 0.0009 \mathrm{~h}^{-1}\right)$ was similar to elimination in water alone $\left(k_{\theta}=0.0013 \pm 0.0006 \mathrm{~h}^{-1}\right)$. For mysids exposed to BaP, the elimination was approximately four times greater in the presence of food $\left(k_{\theta}=0.042 \pm 0.003 \mathrm{~h}^{-1}\right)$ relative to those exposed to water alone $\left(k_{g}=0.0098 \pm 0.0016 h^{-1}\right)$. Further, mysids that produced fecal pellets had significantly lower BaP concentrations than those not producing fecal pellets (Table 1), while HCB concentrations did not differ for the two groups. Elimination for both compounds in the presence of $I$. flocculosa appeared to be dominated by the fecal route based on the concentration found in the fecal pellets (Figure 6).

As with $\underline{D}$. pulex as a food source, elimination of fecal material with $I$. flocculosa as a food source resulted in greater $\mathrm{BaP}$ elimination than $\mathrm{HCB}$ elimination. Although the previous discussion suggests that fecal elimination only occurs for BaP, the elimination of $\mathrm{HCB}$ also appeared to occur in part via a fecal route. However, BaP was eliminated earlier and achieved maximum fecal elimination earlier than HCB. 
A

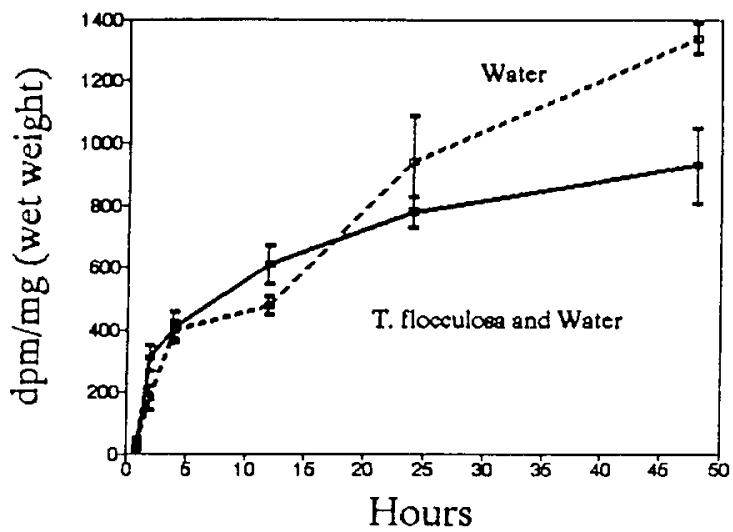

B

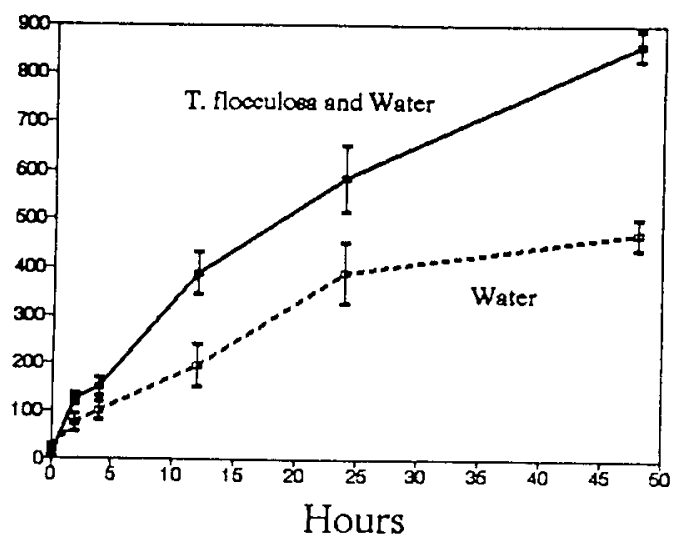

Figure 5. The accumulation of benzo(a)pyrene (A) and hexachlorobiphenyl $(B)$ in the presence and absence of I. flocculosa.

The calculated biological half-lives of HCB were not statistically different for mysids consuming $\mathrm{I}$. flocculosa and $\underline{D}$. pulex compared to the water controls. However, the half-lives of BaP for mysids consuming food sources were significantly reduced by 2 to 10 times compared to the water controls. Additionally, the half-life of BaP was 6 to 35 times smaller than that for HCB (Table 2).

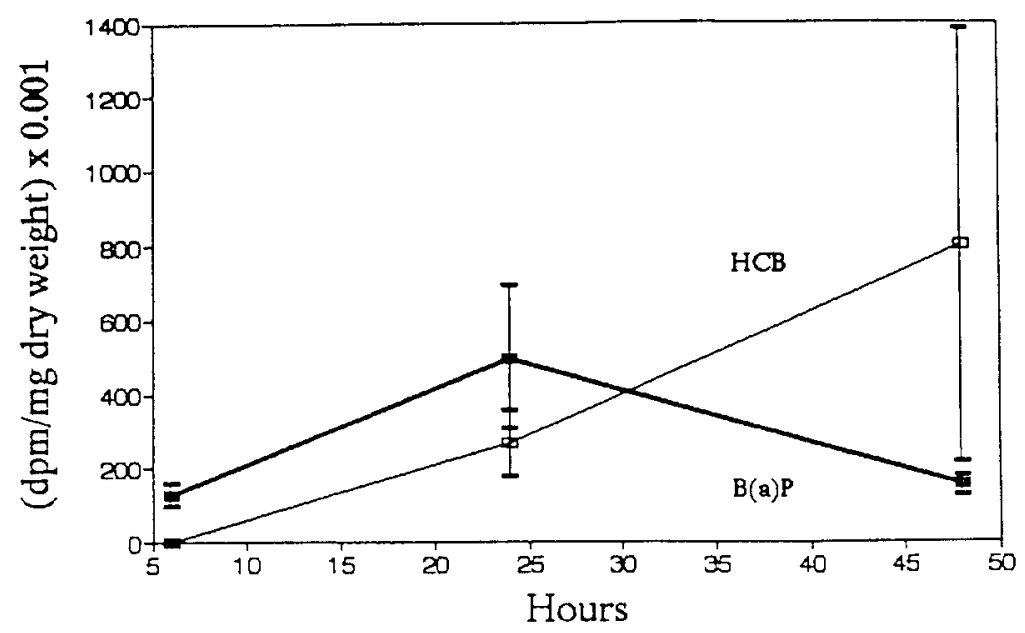

Figure 6. Concentration of benzo(a)pyrene and hexachlorobiphenyl in fecal material eliminated by $\underline{M}$. $\underline{\text { relicta }}$ feeding on $I$. flocculosa. 
Table 1. Concentrations of Benzo(a)pyrene and Hexachlorobiphenyl in M. relicta related to fecal pellet production

\begin{tabular}{|c|c|c|}
\hline & 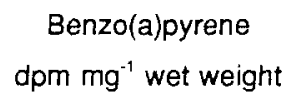 & $\begin{array}{l}\text { Hexachlorobiphenyl } \\
\mathrm{dpm} \mathrm{mg}^{-1} \text { wet weight }\end{array}$ \\
\hline Fecal Pellet Production & $228 \pm 92^{\prime}(11)^{2}$ & $434 \pm 52(10)$ \\
\hline No Fecal Pellet Production & $402 \pm 178^{1}(4)$ & $483 \pm 96(5)$ \\
\hline
\end{tabular}

1. Significantly different $(\alpha=0.05)$

2. Numbers in parentheses represent number of replicates

\section{Discussion}

Feeding Rates: Selection of the food sources to test with mysids reflects the general omnivorous feeding habits of the organism. The cladoceran ‥ pulex was chosen as a representative zooplankton food source because in the field it is consumed by Mysis relicta at high rates (Bowers and Vanderploeg 1982). As a consequence, it is likely to contribute to the contaminant body burden of foraging mysids. The diatom, Tabellaria flocculosa, was chosen as an algal surrogate due to the preference of $\underline{M}$. relicta for larger diatoms (Bowers and Vanderploeg 1982, Bowers and Grossnickle 1978) and the importance of diatoms in the Great Lakes system. The mysids feed well on both sources confirming their omnivorous habits. Both food sources strongly affected the toxicokinetics of non-polar contaminants in the mysid.

Table 2. Food and water dependent half-Lives $\left(\mathrm{t}_{1 / 2}\right)$ for $\underline{\mathrm{M}}$. relicta previously exposed to benzo(a)pyrene and hexachiorobiphenyl in water

\begin{tabular}{|l|c|c|}
\hline Exposure Regime & Half-life Benzo(a)pyrene $(\mathrm{h})$ & Half-life Hexachlorobiphenyl (h) \\
\hline I. flocculosa and water & $17 \pm 1(3)^{1}$ & $576 \pm 203(3)$ \\
\hline Water Controls & $72 \pm 13(3)$ & $347(2)$ \\
\hline D. pulex and water & $28 \pm 1(3)$ & $463 \pm 327(3)$ \\
\hline Water Controls & $132 \pm 26(3)$ & $147 \pm 87(3)$ \\
\hline
\end{tabular}

1. Numbers in parentheses equals number of replicates.

The controlling factors for the observed feeding rates for both food types are not well defined. However, an inflection point in the curve occurs for both food types at approximately 10 to 15 hours, suggesting that the 
feeding rate may depend on satiation. Such a "gut-fullness" hypothesis is not particularly novel. However, it must considered because changes in feeding rates can affect the accumulation of contaminant from food and, consequently, confound the uptake clearance coefficient from food $\left(k_{k}\right)$.

Within the first $10 \mathrm{~h}$ of the experiments, the average number of $\underline{\mathrm{D}}$. pulex consumed per hour compared favorably with in situ predation rates of $1.84 \pm 0.95$ cladocerans consumed per hour (Bowers and Vanderploeg 1982). The feeding rates expressed as the percentage of mysid dry weight consumed per hour also agree with those determined by Bowers and Vanderploeg (1982). The feeding rates appear to depend on the food type offered. $\underline{M}$. relicta fed on $\underline{I}$. flocculosa almost three times as much as they did on $\underline{\underline{Q}}$. pulex. This difference may be due in part to daphnia's enhanced escape capability. A similar mechanism is attributed to mysid's prey selection of cladocerans over copepods by (Bowers and Vanderploeg 1982). Alternatively, differential feeding rates may be controlled by food preferences that may in turn be driven by chemoreceptive mechanisms. Identification of the mechanisms actually controlling the feeding rate and producing the observed differences requires further research.

Toxicokinetics: The apparent increase in the BaP concentration in the $\underline{D}$. pulex food source may be related to a buildup of metabolic products in the animal. This mechanism for BaP accumulation is reasonable, given that $\mathrm{BaP}$ metabolites are reactive and bind to macromolecules. Metabolite buildup has been observed in invertebrates including mysids (Gardner et al. 1990) and chironomids (Leversee et al. 1982) with BaP metabolism. The decrease in contaminant concentrations in the water indicates that the mass balance kinetics approach must be used.

The consumption of contaminated food increased the HCB body burden of $\underline{M}$. relicta by a factor of almost two. The relatively large increase in $\mathrm{HCB}$ from a food source is explained in part because $\underline{\mathrm{M}}$. relicta is not able to eliminate the compound rapidly, even when fed a clean food supply. These findings suggest HCB mobility within the animal is restricted, and once accumulated, remains associated with the animal. The consumption of $\underline{\mathrm{D}}$. pulex contaminated with BaP does not increase but rather reduces the BaP body burden for $\underline{\mathrm{M}}$. relicta. Elimination experiments show that BaP concentrations are substantially reduced by consumption of this food source.

Similar changes in mysid toxicokinetics are observed when I. flocculosa is used as the food source in place of $\underline{D}$. pulex, however, the elimination rate constants are considerably larger with $\underline{I}$. flocculosa. This difference most likely results from the increased mass feeding rates for $\underline{M}$. relicta feeding on the diatom compared to feeding on $\underline{D}$. pulex. The more rapid elimination rate for animals feeding on $\underline{I}$. flocculosa may be partially related to the rate of food movement through the gut, coupled with the increased sorptive capacity of diatom frustules, as compared to cladoceran carapaces. In support of this hypothesis, the more rapid consumption of I. flocculosa appearers to be related to more frequent fecal pellet production. Such increases in elimination with feeding have also been found in fish exposed to BaP (Jimenez et al. 1987).

The differential metabolism of these compounds also explains some of the differences in their kinetic behaviors. However, feeding coupled with fecal elimination appears to be necessary to maintain these differences. Overall, the results suggest that during feeding, the HCB body burden is likely to increase while 
the $\mathrm{BaP} / \mathrm{BaP}$ metabolite body burden will decrease. The increase in accumulation of the non-metabolizable chlorinated biphenyls with feeding is supported by the concurrence of a food chain accumulation model for PCBs with field observations (Connolly 1991).

Elimination and Metabolism: $\underline{M}$. relicta is not able to biotransform HCB to any substantial extent. While biotransformation of PCBs occur in aquatic animals, it is usually restricted to the less chlorinated congeners (Melanchion and Lech 1976). Thus, HCB biotransformation is not expected, and it has been found to be extremely recalcitrant based on a wide range of studies with a variety of organisms. Alternatively, $\underline{M}$. relicta biotransformed BaP at $2.4 \mathrm{pmol} \mathrm{g}^{-1} \mathrm{dry} w \mathrm{wt}^{-1}$. The mixed function oxidase enzymes required to biotransform xenobiotics have been reported for other aquatic invertebrates (Singer and Lee 1977, Stegeman and Kaplan 1981, and Kreiger and Lee 1973) and the capability to biotransform BaP, in particular, has been reported for

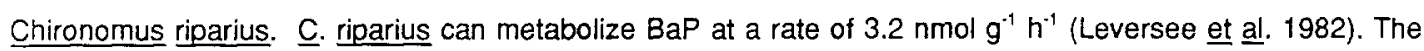
difference in metabolic rate between the chironomids and mysids can be attributed to the exposure, $0.6-1 \mu \mathrm{g}$ $L^{-1}$ for chironomids and $4 \mathrm{ng} \mathrm{L^{-1 }}$ for mysids, a difference of a factor of 250 and the differences in temperature $25^{\circ} \mathrm{C}$ for chironomids and $4^{\circ} \mathrm{C}$ for mysids. Additionally, the amphipod Hyalella azteca metabolizes the PAH anthracene at a rate of $2.4 \mathrm{nmol} \mathrm{g} \mathrm{g}^{-1} \mathrm{dry}$ wt. $\mathrm{h}^{-1}$ (Landrum and Scavia 1983). Again, these rates compare favorably with the rate for BaP metabolism by $\underline{\mathrm{M}}$. relicta of $2.4 \mathrm{pmol} \mathrm{g}^{-1}$ dry wt. $\mathrm{h}^{-1}$ if differences in exposure and temperature are considered. Finally, the metabolic rate for mysids in this experiment was approximately ten times that for non-fed mysids exposed at somewhat lower concentrations 1 to $2 \mathrm{ng} \mathrm{L}^{-1}$ (Gardner et al. 1990).

The overall effect of such BaP biotransformation by $\underline{M}$. relicta appears to be the enhanced potential for metabolite elimination. However, such elimination appears to also require coupled fecal material production to realize the full elimination potential. The dependence on fecal elimination may be the result of the absence of a functional kidney, typically used to eliminate polar metabolites in higher trophic level organisms. The loss of xenobiotic compounds via a fecal route may be due to their incorporation in the peritrophic membrane that encases the feces (Maucheline 1980). This mechanism has been postulated in the loss of p,p'-DDT residues from mosquito larvae (Abedi and Brown 1961).

Elimination and Feeding: Enhanced elimination with feeding has been reported by other investigators. Anthracene elimination is accelerated by consumption of a sediment for the amphipod Hyalella azteca (Landrum and Scavia 1983). Similarly, the midge, Chironomus riparius, exhibited increased elimination of BaP while feeding on a paper towel substrate (Leversee et al. 1982). Although fecal material was not collected for either study, it is likely that mechanisms (i.e., biotransformation and fecal elimination) similar to those operative in $\underline{M}$. relicta are involved.

In $\underline{\mathrm{M}}$. relicta, BaP accumulation and elimination can be conceptualized as a multi-compartment process. Uptake and elimination of $\mathrm{BaP}$ occurs via both food and water routes. The majority of the accumulated material eliminated in the feces appears to be metabolites. The TLC of the water extracts suggests that parent material is eliminated directly to the water. These findings suggest that different mechanisms operate based on the nature of molecule. 
Molecular specific elimination mechanisms appear to be primarily responsible for the observed differences in the $k_{a}$ estimates of BaP and HCB. Additionally, $k_{a}$ measured for BaP appears to be related to the type of food

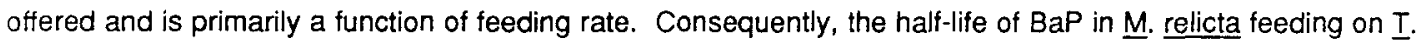
flocculosa is reduced by almost a factor of two compared to mysids feeding on $\underline{\mathrm{D}}$. pulex. Further, the HCB halflife is 17 to 33 times that of $\mathrm{BaP}$ and does not depend on the food source. These observations are significant for estimating bioconcentration factors (BCF) for hydrophobic chemicals from log octanol:water partition coefficients. Indeed, if the increased elimination via feeding is ignored, the mysid BCF may be over-estimated by as much as one order of magnitude.

Our results have important implications for the interpretation of toxicant concentrations for field collected $\underline{M}$. relicta. The increased elimination of $\mathrm{BaP}$ and metabolites associated with a diatom suggests that the compound's concentration and potentially toxic metabolites are lowest during periods of diatom abundance. Consequently, seasonally dependent toxic responses may occur that are driven primarily by varying internal toxicant doses as a function feeding-mediated elimination. Alternatively, although feeding can presumably increase the concentration of $\mathrm{HCB}$ in the animal, feeding-mediated elimination is not important and therefore concentrations and the potential toxicity of $\mathrm{HCB}$ are expected to be directly related to concentrations in the food source.

Feeding and Accumulation: Initially, the feeding rate constants, $k_{1}$, were determined by solving Equation 5 for $k_{1}$. However, this approach resulted in estimates of $k_{1}$ for both food types that exceeded all the experimentally determined feeding rates. This finding posed a dilemma in that the assimilation efficiency (defined as the ratio of the uptake clearance to the feeding rate) was substantially greater than $100 \%$. Conceptually, these results mean that the amount of assimilated contaminant would exceed the total amount of contaminant consumed by the animal. Because of this contradiction, the numerical calculation of $k_{1}$ must not be the appropriate model to use to estimate the real $k_{1}$. Additionally, without an estimate of $k_{1}$, one is not able to estimate the assimilation efficiency.

An examination of the $k_{1}$ expression suggests that $k_{1}$ would be overestimated if (1) the rate of accumulation $\left(d C_{a} / d t\right)$ is overestimated, (2) the product $k_{w} C_{w}$ is underestimated, (3) $C_{f}$ is underestimated, or (4) the product $\mathrm{k}_{\mathrm{e}} \mathrm{C}_{\mathrm{a}}$ is overestimated. In this experimental design, $\mathrm{k}_{w}$ is estimated by application of the reference $k_{w}$ to the feeding animals. Indeed, the activity of feeding may accelerate the flow of contaminant past the animal and hence elevate $k_{w}$ for feeding organisms relative to non-feeding organisms. This scenario may be plausible if contaminant uptake is proportional to increases in respiration rates due to feeding. Earlier studies suggest that respiration rates are partially related to the uptake clearances from water for BaP and HCB in Mysis relicta (Landrum et al. 1992). Therefore, $\mathrm{k}_{\mathrm{w}}$ may differ substantially during feeding due to respiration rate changes. Additionatly, if uptake can occur across the carapace and is diffusion limited, then animals passing through a greater water volume during prey search and selection may increase their contaminant body burden and consequently show an increased $k_{w}$.

To test the general hypothesis that $k_{w}$ with and without feeding are essentially the same, the experimentally determined feeding rates were substituted into the $k_{1}$ expression, assuming that the observed feeding rates were 
equal to $k_{1}$ and $x$ enobiotic assimilation efficiencies were $100 \%$. The uptake clearances $\left(k_{w}\right)$ were then calculated from the expressions and compared to the measured reference $k_{w}$ values. The calculated $k_{w}$ was not statistically different from the experimentally determined $k_{w}$ (Table 3 ). However, the

Table 3. Comparison of derived $\left(k_{w 1}\right)$ and experimental $\left(k_{w 2}\right)$ uptake clearance constants $\left(k_{w}\right)$ from water for Mysis relicta.

\begin{tabular}{|l|c|c|c|c|}
\hline \hline Food Type & \multicolumn{2}{|c|}{ Benzo(a)pyrene } & \multicolumn{2}{c|}{ Hexachlorobiphenyl } \\
\hline & $k_{w 1}\left(\mathrm{ml} \mathrm{g}^{-1} \mathrm{~h}^{-1}\right)$ & $k_{w 2}\left(\mathrm{ml} \mathrm{g}^{-1} \mathrm{~h}^{-1}\right)$ & $k_{\mathrm{w} 1}\left(\mathrm{ml} \mathrm{g}^{-1} \mathrm{~h}^{-1}\right)$ & $k_{\mathrm{w} 2}\left(\mathrm{ml} \mathrm{g}^{-1} \mathrm{~h}^{-1}\right)$ \\
\hline I. flocculosa & $90 \pm 61$ & $113 \pm 111$ & $98 \pm 50$ & $130 \pm 90$ \\
\hline D. pulex & $87 \pm 30$ & $56 \pm 31$ & $131 \pm 12$ & $75 \pm 49$ \\
\hline
\end{tabular}

variability in the estimates was so large that it was not possible to tell whether the uptake clearance was altered. Consequently, it appears that the substitution of the control $k_{w}$ into the $k_{4}$ expression is valid, and an alternative model must be used for estimating $k_{1}$.

If the experimentally obtained feeding rates are substituted for $k_{q}$ under the assumption that the assimilation efficiencies are equal to 1.0 , then the percentage of contaminant obtained from food is at the most $41 \%$ (Table

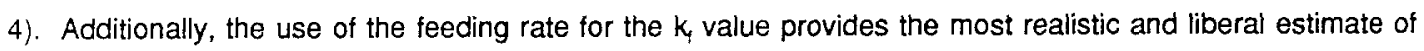
the fraction of contaminant obtained from a food source for this animal. As presented, a greater fraction of $\mathrm{HCB}$ is derived from both $\underline{D}$. pulex and I. flocculosa compared to BaP. These observations may be explained by differential molecular transfer throughout the animal because of substantial differences in the stereochemistry and electronegativity of the molecules.

Table 4. Estimated percentages of benzo(a)pyrene and hexachlorobiphenyl obtained from food using the measured feeding rates $\left(k_{1}\right)$.

\begin{tabular}{|l|c|c|}
\hline & \multicolumn{2}{|c|}{ Percent Obtained From Food } \\
\hline Food Type & Benzo(a)pyrene & Hexachlorobiphenyl \\
\hline D. pulex & $22 \pm 17$ & $41 \pm 32$ \\
\hline I. flocculosa & $17 \pm 10$ & $29 \pm 24$ \\
\hline
\end{tabular}

More $\mathrm{HCB}$ and BaP are estimated to be obtained from $\underline{\mathrm{D}}$. pulex than from I. flocculosa. This difference may be related to higher feeding rates on $I$. flocculosa. Mechanistically, this hypothesis implies that the gut residence time for $\underline{I}$. flocculosa mass is less than that for $\underline{D}$. pulex. A reduced residence time of food in the gut may consequentily restrict the time necessary for enzymatic processes to degrade gut materials and transfer associated contaminant to the tissues. Conversely, an increase in the gut residence time (as hypothesized for 
D. pulex) would permit a more extensive digestive process and subsequent contaminant transfer with an apparent increased accumulation of contaminant from food. It is also possible that the surface areas of the food sources play an important role in determining contaminant bioavailability.

Various estimates of the amount of contaminant derived from the food source have been made. Sediment and associated porewater is estimated to contribute $77 \%$ of the anthracene body burden to the amphipod Hyalella azteca (Landrum and Scavia 1983). It is likely that material sorbed to sediment is less bioavailable than that associated with porewater. Consequently, the actual percentage of anthracene from the sediment food source is probably less than $77 \%$. Additionally, food for fish species such as lake trout and salmon is estimated to contribute up to $90 \%$ of the contaminant load of these animals (Thomann and Connolly 1984 , Weininger 1978), while the marine fish Leiostomus xanthurus, accumulates only $54 \%$ of its PCB body burden from food. In the case of BaP, bluegills are estimated to obtain 40 to $50 \%$ of their dose from food Jimenez et al. 1987). However, fish species (particularly larger individuals) have smaller surface area-to-volume ratios relative to macro-invertebrates. This would reduce the relative contribution from a water source for fish. In studies performed on the smaller fathead minnow Pimephales promelas, a daphnia food source accounted for less than $1 \%$ of the total acridine body burden (Southworth et al. 1979), thus supporting the hypothesis that food does not contribute substantially to the xenobiotic body burden of aquatic animals.

The results presented in this study suggest that at most, food contributes less than $45 \%$ of the contaminant input to Mysis relicta. Consequently, mathematical models assuming a $90 \%$ contribution from food to the xenobiotic body burden of macro-invertebrates may overestimate the extent of food contribution by a factor of at least a factor of two and may not account for feeding induced changes in compound elimination.

\section{ACKNOWLEDGEMENTS}

We wish to thank the crew of the R/N Shenehon for assistance in collecting mysids. We also wish to thank Wendy Dupuis for technical assistance. GLERL contribution number 797

\section{REFERENCES}

Abedi, Z. H. and A. A. Brown. 1961. Peritrophic membrane as a vehicle for DDT and DDE excretion in Aedes aegypti larvae. Ann. Ent. Soc. Amer. 54:539.

Beeton, A. M. and Bowers, J. A. 1982. Vertical migration of Mysis relicta(Loven), Hydrobiologia 93:53-61.

Biddinger, G. R. and S. P. Gloss. 1984. The importance of trophic transfer in the bioaccumulation of chemical contaminants in aquatic ecosystems. Residue Reviews 91:103-145.

Bowers, J. A. and N. E. Grossnickle. 1978. The herbivorous habits of Mysis relicta in Lake Michigan. Limnol. Oceanogr. 23:767-776.

Bowers, J. A. and H. A. Vanderploeg. 1982. In situ predatory behavior of Mysis relicta in Lake Michigan. Hydrobiologia 93:121-131.

Connolly, J. P. 1991. Application of a food chain model to polychlorinated biphenyl contamination of the lobster and wither flounder food chains in New Bedford Harbor. Environ. Sci. Tech. 25:760-770.

Connolly, J. P. and C. J. Pedersen. 1988. A thermodynamic-based evaluation of organic chemical accumulation 
in aquatic organisms. Environ. Sci. Tech. 22:99-103.

Connolly, J. P. and R. Tonelli. 1985. Modeling kepone in the striped bass food chain of the James River Estuary.

Est. Coast. Shelf Sci. 20:349-366.

Dryer, W. R., L. F. Erkkila and C. L. Tetloff. 1965. Food of lake trout in Lake Superior. Trans. Am. Fish. Soc. 94:169-176.

Fisher, D. J. and J. R. Clark. 1990. Bioaccumulation of kepone by grass shrimp (Palaemontes pugio): importance of dietary accumulation and food ration. Aquatic Toxicol. 17:167-186.

Gardner, W. S., P. F. Landrum and J. F. Cavaletto. 1990. Lipid-partitioning and disposition of benzo(a)pyrene and hexachlorobiphenyl in Lake Michigan Pontoporeia hoyi and Mysis relicta. Environ. Toxicol. Chem. 9:1269-1278.

Gobas, F. A. P. C., D. C. G. Muir and D. Mackay. 1988. Dynamics of dietary bioaccumulation and fecal elimination of hydrophobic organic chemicals in fish. Chemosphere 17:943-962.

Jimenez, B. D., C. P. Cirmo, and J. F. McCarthy. 1987. Effects of feeding and temperature on uptake, elimination and metabolism of benzo(a)pyrene in the bluegill sunfish (Lepomis macrochirus). Aquatic Toxicol. 10:41-57.

Kreiger, R. I. and P. W. Lee. 1973. Properties of the aldrin epoxidase system in the gut and fat body of a caddisfly larvae. J. Econ. Entomol. 66:1-6.

Landrum, P. F. 1983. The effect of co-contaminants on the bioavailability of polycyclic aromatic hydrocarbons to Pontoporeia hovi. In: Polynuclear Aromatic Hydrocarbons: Formation, Metabolism, and Measurement, M. Cooke and A.J. Dennis, eds., Battelle Press, Columbus, $\mathrm{OH}$, pp. 731-743

Landrum P. F. and D. Scavia. 1983. Influence of sediment on anthracene uptake, elimination, and biotransformation by the amphipod, Hyalella azteca. Can. J. Fish. Aquat. Sci. 40:298-305.

Landrum, P. F., W. A. Frez, and M. S. Simmons. 1992. Relationship of toxicokinetic parameters to respiration rates in Mysis relicta. J. Great Lakes Res. 18:331-339.

Leversee, G. L., J. P. Giesy, P. F. Landrum, S. Gerould, T. E. Fannin, J. D. Haddock, and S. M. Bartell. 1982. Kinetics and biotransformation of benzo(a)pyrene in Chironomus riparius. Arch. Environ. Contam. Toxicol. 11:25-31.

Macek, K. J. and S. Korn. 1970. Significance of the food chain in DDT accumulation by fish. J. Fish. Res. Bd. Can. 27:1496-1498.

Macek, K. J., C. R. Rodgers, D. L. Stalling, and S. Korn. 1970. The uptake, distribution and elimination of dietary ${ }^{14} \mathrm{C}$-DDT and ${ }^{14} \mathrm{C}$-dieldrin in rainbow trout. Trans. Am. Fish. Soc. 99:689-695.

Maucheline J. 1980. The Biology of Mysids and Euphausiids. In: Advances in Marine Biology, Vol. 18, J. H. S. Blaxter, F. S. Russel and M. Yonge, eds. Academic Press, New York. p 92.

Melancon, M. J. and J. J. Lech. 1976. Isolation and identification of a polar metabolite of tetrachlorobiphenyl from bile of rainbow trout exposed to ${ }^{14} \mathrm{C}$-tetrachlorobiphenyl. Bull. Environ. Contam. Toxicol. 15:181-188.

Neff, J. M. 1979. Polycyclic Aromatic Hydrocarbons in the Marine Environment: sources Fate and Biological Effects. Applied Science Publishers, London, $262 \mathrm{pp}$.

Opperhuizen, A., and S. M. Schrap. 1988. Uptake efficiencies of two polychlorobiphenyls in fish after dietary exposure to five different concentrations. Chemosphere 17:253- 262. 
Opperhuizen, A. 1991. Bioaccumulation kinetics: Experimental data and modeling. In: Organic Micropollutants in the Aquatic Environment. Proceedings of the Sixth European Symposium, G. Angeletti and A. Bjorseth, Eds., Kluwer Academic Publishers, pp.61-70.

Rasmussen, J. B., D. J. Rowan, D. R. S. Lean, and J. H. Carey. 1990. Food chain structure in Ontario lakes determines PCB levels in lake trout (Salvelinus namaycush) and other pelagic fish. Can J. Fish Aquat. Sci. 47:2030-2038.

Rhead, M. M., and J. M. Perkins. 1984. An evaluation of the relative importance of food and water as sources of $p, p^{\prime}$-DDT to the goldfish, Carassius auratus (L.). Water Res. 18:719-725.

SAS Institute Inc. 1985. Users Guide to Statistics, 5th ed., Cary, NC.

Singer, S. C. and R. F. Lee. 1977. Mixed function oxygenase activity in the blue crab, Callinectes sapidus: Tissue distribution and correlation with changes during molting and development. Biol. Bull. Woods Hole, Mass. 153:377-386.

Smith, W. E. 1970. Tolerance of Mysis relicta to thermal shock and light. Trans. Am. Fish. Soc., 2:418-422.

Southworth, G. R., D. R. Parkhurst, and J. J. Beaucamp. 1979. Accumulation of acridine from water, food, and sediment by the fathead minnow Phimephales promelal. Water Air Soil Pollut. 12:331-341.

Stegeman, J. J. and H. B. Kaplan. 1981. Mixed function oxygenase activity and benzo(a)pyrene metabolism in the barnacle Balanus eburneus (Crustacea: Ciripedia). Comp. Biochem. Physiol. 68C:55-62.

Stein, J. R. 1973. Handbook of Phycological Methods. Cambridge University Press, N.Y., N.Y.

Thomann R. V., and J. P. Connolly. 1984. Model of PCB in the Lake Michigan lake trout food chain. Environ. Sci. Tech. 18:65-71.

Weininger, D. 1978. Accumulation of PCBs by lake trout in Lake Michigan. Ph. D. Thesis, University of Wisconsin, Madison, Wi., $232 \mathrm{pp}$.

Wells, L. and A. M. Beeton. 1963. Food of the bloater, Coregonus hoyi, in Lake Michigan, Trans. Am. Fish. Soc. 92:245-255.

Weston, D. P. 1990. Hydrocarbon bioaccumulation from contaminated sediment by the deposit-feeding polychaete Abarenicola pacifica. Mar. Biol. 107:159-170. 